\title{
Safety and toxicology of the intravenous administration of Ang2-siRNA plasmid chitosan magnetic nanoparticles
}

\author{
XIUYING SHAN ${ }^{1}$, TINGTING XU ${ }^{1}$, ZHAOLIANG LIU ${ }^{1}$, XUEFENG HU ${ }^{2}$, YAN-DING ZHANG ${ }^{2}$ and BIAO WANG ${ }^{1}$ \\ ${ }^{1}$ Department of Plastic Surgery, The First Affiliated Hospital of Fujian Medical University, Fuzhou, Fujian 350005; \\ ${ }^{2}$ College of Life Sciences, Fujian Normal University, Fuzhou, Fujian 350108, P.R. China
}

Received October 26, 2015; Accepted November 4, 2016

DOI:10.3892/mmr.2016.6090

\begin{abstract}
This aim of the present study was to investigate the safety and toxicology of intravenous administration of angiopoietin-2 (Ang2)-small interfering (si)RNA plasmid-chitosan magnetic nanoparticles (CMNPs). Ang2-CMNPs were constructed and subsequently administered at different doses to mice and rats via the tail vein. The acute (in mice) and chronic toxicity (in rats) were observed. The results of the acute toxicity assay revealed that the $\mathrm{LD}_{50}$ mice was $>707.0 \mathrm{mg} \cdot \mathrm{kg}^{-1} \cdot \mathrm{d}^{-1}$, and the general condition of mice revealed no obvious abnormalities. With the exception of the high dose group $\left(254.6 \mathrm{mg} \cdot \mathrm{kg}^{-1} \cdot \mathrm{d}^{-1}\right)$, which exhibited partial lung congestion, the other groups exhibited no obvious abnormalities. Results of the chronic toxicity assay demonstrated that the non-toxic dose of Ang2-CMNPs in the rat was $>35.35 \mathrm{mg} \cdot \mathrm{kg}^{-1} \cdot \mathrm{d}^{-1}$ for 14 days. The rat general condition and blood biochemistry indexes revealed no obvious abnormality. The blood routine indexes and lung/body ratio of each treatment group were higher when compared with the control group. The middle- and high-dose groups exhibited chronic pulmonary congestion, whilst the low-dose and control groups exhibited no abnormality. Similarly, the other organs revealed no obvious abnormality. Ang2-CMNPs have good safety at a certain dose range and may be considered as the target drug carrier.
\end{abstract}

\section{Introduction}

The incidence of malignant cancer types in China demonstrates an upward trend, and is increasing at an average rate of $3-5 \%$ annually (1). Melanoma is a form of superficial tumor, with a high malignancy and difficulty to treat (2). Currently, no effective prevention and treatment methods

Correspondence to: Dr Biao Wang, Department of Plastic Surgery, The First Affiliated Hospital of Fujian Medical University, 20 Chazhong Road, Fuzhou, Fujian 350005, P.R. China

E-mail: docbiaowang@126.com

Key words: Ang2 plasmid, siRNA, chitosan magnetic nanoparticles, toxicity exist (3). The traditional surgical treatment methods lead to surgical trauma. The magnetic targeted drug delivery system (MTDDS) has provided a novel avenue for cancer therapy, and has become a priority of domestic and foreign pharmaceutical research (4). MTDDS is a stable system composed of a magnetic substance and drugs, using a suitable carrier. Under the external magnetic field with a specific intensity, the drug may be directionally moved, positioned, concentrated and released in vivo towards the lesions, thereby exerting its efficacies at the lesion site (5). The highly specific characteristic of this system has been previously demonstrated to significantly reduce the side effects (6).

The present study used self-made angiopoietin-2 (Ang2)-small interfering (si)RNA plasmid-chitosan magnetic nanoparticles (CMNPs) with the aim of inhibiting the growth of malignant melanoma. However, its safety remains to be investigated. Ang2-CMNPs have magnetic iron oxide nanoparticles as their core and are wrapped in chitosan polysaccharides to adsorb to the Ang2-siRNA plasmid vector, thus forming the magnetic nanoparticle carrier. This particle is nano-grade, so its features are making nanomaterials more readily absorbed in vivo, as well as entry into the blood circulation (7). A previous study (8) demonstrated that nanoparticles may penetrate the blood-brain-barrier by passive transferring, vector-mediation or phagocytosis, thereby exhibiting certain impacts on the body. Therefore, it is necessary to perform a comprehensive safety evaluation on nanomaterials. However, no research institute thus far has performed a full and systematic evaluation towards the safety of nanomaterials, and the data concerning the potential toxicity are scarce. The present study predominantly investigated the acute and chronic toxicity of Ang2-CMNPs, aiming to examine their safety and provide a theoretical basis for their application in tumor-targeted therapy.

\section{Materials and methods}

Preparation of CMNPs. A total of $0.15 \mathrm{~g}$ of magnetic $\mathrm{Fe}_{3} \mathrm{O}_{4}$ nanoparticles (Fuzhou Maixin Biotechnology Development Co.,Ltd.,Fuzhou, China) were dispersed in $20 \mathrm{ml} 1.5 \%$ chitosan solution (CS; molecular weight, 1.38x106; 90\% deacetylation; Zhejiang Aoxing Biotechnology Co., Ltd., Hangzhou, China) by ultrasound and stirring. Subsequently, $80 \mathrm{ml}$ liquid paraffin and petroleum ether mixture (v/v, 7:5), containing $2 \mathrm{ml} \mathrm{Span}-80$ 
(all provided by Sigma-Aldrich, Merck-Millipore, Darmstadt, Germany), was added, followed by stirring at $40^{\circ} \mathrm{C}$ for $30 \mathrm{~min}$ for sufficient emulsification. A total of $10 \mathrm{ml} 25 \%$ glutaraldehyde (Sigma-Aldrich) solution was slowly added, followed by stirring at $40^{\circ} \mathrm{C}$ for $30 \mathrm{~min}$. $\mathrm{NaOH}$ (1 mol/l) (Sigma-Aldrich) solution was used to adjust the $\mathrm{pH}$ to 9.0 , followed by heating at $40^{\circ} \mathrm{C}$ for $1 \mathrm{~h}$. After thoroughly washing successively with anhydrous ether, acetone, absolute ethanol and distilled water, the CMNPs were obtained.

Preparation of Ang2-CMNPs. A total of $1 \mathrm{mg}$ CMNPs was added to $1 \mathrm{ml}$ PBS buffer (pH 7.4; Sigma-Aldrich), followed by ultrasonic oscillation for $3 \mathrm{~min}$. Subsequently, $2 \mathrm{ml}$ polylysine (diluted in PBS buffer to a concentration as $0.1 \mathrm{mg} / \mathrm{ml}$; Sigma-Aldrich) was added, followed by mixing well and incubation at room temperature for $10 \mathrm{~min}$. An Ang2-siRNA plasmid (Fig. 1; Fuzhou Maixin Biotechnology Development Co., Ltd.) was mixed with polylysine-modified CMNPs, to a ratio of $1: 1,1: 10,1: 100$ or $1: 1,000$, followed by incubation at room temperature for $1 \mathrm{~h}$. Ang2-CMNPs were transfected into human malignant melanoma cells. Following transfection, the cells were observed using fluorescence microscopy and the transfection efficiency was calculated by cell counting.

Acute toxicity assay. A total of 60 Kunming mice (30 male and 30 female; weight, 18-22 g, specific-pathogen-free grade) were purchased from Shanghai Experimental Animal Center, [Shanghai, China; license number SCXK (Min) 2012-0001]. The animals were house under the following conditions: Temperature, $25 \pm 1{ }^{\circ} \mathrm{C}$; humidity, 50-60\%; 12:12 light:dark cycles. The animal experiments were approved by the Institutional Animals Ethics Committee of Fujian Medical University (Fuzhou, China). The mice were randomly divided into six groups (10 mice/group; male/female ratio, 1:1). The mice were fasted with free access to water for the $12 \mathrm{~h}$ prior to the experiment. Ang2-CMNPs were divided into five different dose groups. The doses in each were as follows: 91.6, 152.8, 254.6, 424.2 and $707.0 \mathrm{mg} \cdot \mathrm{kg}^{-1} \cdot \mathrm{d}^{-1}$ (groups 1-5, respectively). A total of $0.4 \mathrm{ml} \mathrm{Ang2-CMNPs} \mathrm{in} \mathrm{suspension}$ with normal saline was injected into the mice via the tail vein, while the control group was injected with an equal volume of normal saline. Diet and body weight changes of each group were observed for 14 consecutive days, as well as whether any mice died during experimentation. Following experimentation, the mice were sacrificed by cervical dislocation and two mice from each group were randomly selected for dissection to observe the color and shape of the gross specimen. The major organs, including heart, liver, spleen, lungs and kidneys were performed underwent pathological examinations. Hematoxylin and eosin (H\&E) staining, and Prussian blue staining (Fuzhou Maixin Biotechnology Development Co., Ltd., Fuzhou, China) were performed, according to the manufacturer's protocols, to observe the conditions of edema, deformation, necrosis and iron-particle deposition in cells.

Chronic toxicity assay. A total of 40 Sprague-Dawley rats (20 male and 20 female; weight, 90-100 g; specific-pathogen-free grade) were purchased from Shanghai Experimental Animal Center [Shanghai, China; license number SCXK (Min) 2012-0001]. The rats were randomly divided into low-, middle- and high-dose groups, and a control group (10 rats/group; male/female ratio, 1:1) and allowed free access to food and water. The control group was injected with saline, while the low-, middle- and high-dose groups were injected with $1 \mathrm{ml}$ Ang2-CMNP suspension (35.35, 70.70 and $353.50 \mathrm{mg} \cdot \mathrm{kg}^{-1} \cdot \mathrm{d}^{-1}$, respectively) via the tail vein. The injection was performed for 14 consecutive days. Following the initiation of medication, the response of the rats was observed and they were weighed once every 3 days to monitor weight changes. On day 15, the medication was stopped and the observation was continued for 7 days. On day 21, the rats were sacrificed by cervical dislocation, and the blood was sampled from the eyeball for routine blood tests (red cell count, white cell count, hemoglobin content, blood platelet count) and biochemical tests (blood urea nitrogen, albumin, creatinine-2, alkaline phosphatase, g-glutamyltransferase, alanine aminotransferase, aspartate aminotransferase, total bilirubin-1, total protein). Two rats from each group were selected for dissection to observe the color and shape of the gross specimen. As aforementioned for the acute assay, the major organs, including the heart, liver, spleen, lungs and kidneys, underwent pathological examination, and the organ co-efficient (organ wet weight/body weight; 60 mice) was calculated. H\&E staining and Prussian blue staining were performed to observe the conditions of edema, deformation, necrosis and iron-particle deposition in cells, and the chronic toxicity of the particles.

Statistical analysis. All statistical analysis were performed using SPSS software (version, 17.0; SPSS, Inc., Chicago, IL, USA). The data are presented as the mean \pm standard deviation. Comparisons between two groups were performed using one-way analysis of variance. $\mathrm{P}<0.05$ was considered to indicate a statistically significant difference.

\section{Results}

Confirmation of suitable quality ratio of Ang2/CMNPs. Fluorescence microscopy revealed that when the quality ratio of Ang2/CMNPs ranged between 1:1 to 1:1,000, the red fluorescence of transfected human malignant melanoma cells gradually increased (Fig. 2). When the ratio was 1:100, the red fluorescence was the most intense. The transfection efficiency of Ang2-CMNPs towards malignant melanoma cells is shown in Table I. A ratio of 1:100 was determined to be the appropriate quality ratio of Ang2/CMNPs for subsequent experiments.

Results of the acute toxicity assay. Following administration of Ang2-CMNPs, the mice in the 254.6, 424.2 and $707 \mathrm{mg} \cdot \mathrm{kg}^{-1} \cdot \mathrm{d}^{-1}$ groups exhibited short-term staggering, reduced activity and accelerated breathing. The 91.6, $152.8 \mathrm{mg} \cdot \mathrm{kg}^{-1} \cdot \mathrm{d}^{-1}$ and control groups exhibited no abnormality. No mouse in any group died during experimentation. The body weight gain in each treatment group demonstrated no significant difference when compared with the control group (data not shown).

The naked eye observation indicated that the anterior left lung lobe of the mice in the $254.6 \mathrm{mg} \cdot \mathrm{kg}^{-1} \cdot \mathrm{d}^{-1}$ group was dark red in color and each lung lobe of the mice in the 424.2 and $707 \mathrm{mg} \cdot \mathrm{kg}^{-1} \cdot \mathrm{d}^{-1}$ groups were identical color. The H\&E staining 
Table I. Transfection efficiency of Ang2-CMNPs into human malignant melanoma cells.

\begin{tabular}{lccc}
\hline $\begin{array}{l}\text { Quality } \\
\text { ratio }^{\mathrm{a}}\end{array}$ & $\begin{array}{c}\text { Cell } \\
\text { number }^{\mathrm{b}}\end{array}$ & $\begin{array}{c}\text { Cell } \\
\text { number }^{\mathrm{c}}\end{array}$ & $\begin{array}{c}\text { Transfection } \\
\text { efficiency (\%) }\end{array}$ \\
\hline $1: 1$ & 0 & 118 & 0 \\
$1: 10$ & 10 & 107 & 9.35 \\
$1: 100$ & 63 & 103 & 61.17 \\
$1: 1,000$ & 35 & 84 & 41.67 \\
\hline
\end{tabular}

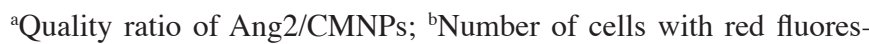
cence under mercury lamp; ${ }^{\mathrm{N}}$ Number of cells under normal light. Ang2-CMNPs, angiopoietin-2-small interfering RNA plasmid chitosan magnetic nanoparticles.

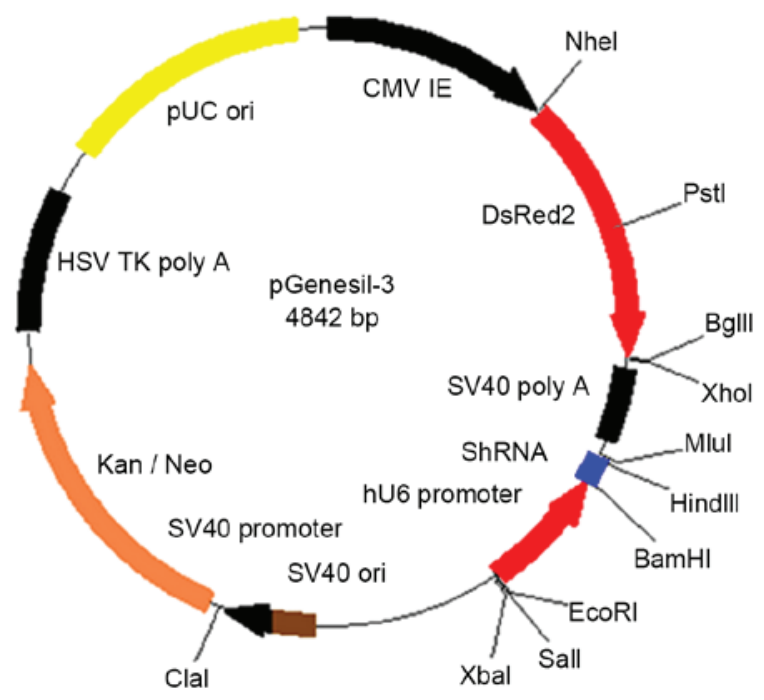

Figure 1. pGenesil-3 recombinant plasmid (Ang2-siRNA plasmid). A schematic showing the 4,842 bp plasmid used in the present study, including restriction sites and promoter regions. Ang2-siRNA, angiopoietin-2-small interfering RNA.

revealed that the alveolar wall of the mice in the 254.6, 424.2 and $707.0 \mathrm{mg} \cdot \mathrm{kg}^{-1} \cdot \mathrm{d}^{-1}$ groups exhibited telangiectasia, with red blood cells appearing inside the alveolar cavity, presenting signs of pulmonary congestion (Fig. 3). The Prussian blue staining demonstrated that the lungs in the 254.6, 424.2 and $707 \mathrm{mg} \cdot \mathrm{kg}^{-1} \cdot \mathrm{d}^{-1}$ groups were deposited with blue aggregated particles. The lung phagocytes exhibited phagocytosis targeting these particles and the surrounding areas exhibited inflammatory reactions (Fig. 4). The other assessed organs exhibited no abnormality in each group. The control group and the low-dose groups demonstrated no obvious abnormalities.

Results of chronic toxicity assay. Following administration of Ang2-CMNPs, all rats in each group exhibited normal drinking and eating activity, and no animal died throughout the experimental period. The changes in body weight between each treatment group and the control group demonstrated no significant difference $\left(\mathrm{F}_{\phi}=0.85, \mathrm{~F}_{\delta}=0.72, \mathrm{P}>0.05\right)$.

As presented in Table II, the lung/body ratio of treatment groups was significantly higher compared with the control
A

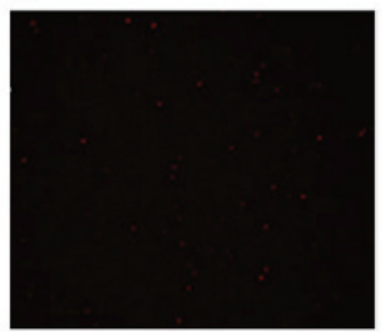

C

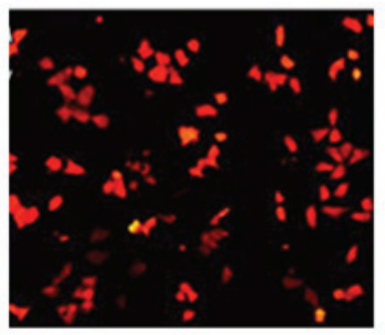

B

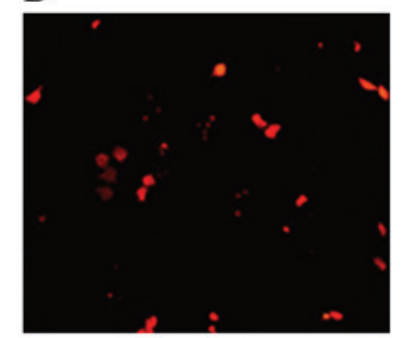

D

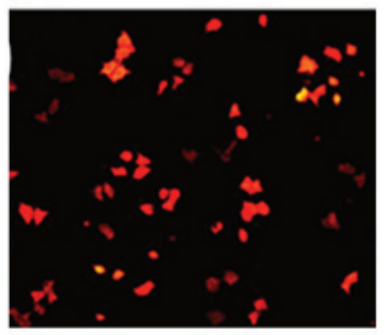

Figure 2. Transfection of Ang2/CMNPs into human malignant melanoma cells. Following transfection, the cells were observed using fluorescence microscopy, and the transfection efficiency was calculated by cell counting. Red signal indicates cells positively transfected with the plasmid. The quality ratio of Ang2/CMNPs was (A) 1:1, (B) 1:10, (C) 1:100 and (D) 1:1,000, respectively (magnification, x100). Ang2/CMNPs, angiopoietin-2-small interfering RNA plasmid chitosan magnetic nanoparticles.
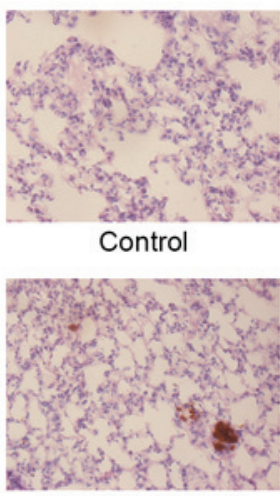

$254.6 \mathrm{mg} \cdot \mathrm{kg}^{-1} \cdot \mathrm{d}^{-1}$

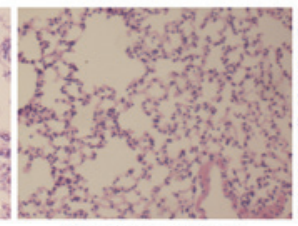

$91.6 \mathrm{mg} \mathrm{kg}^{-1} \cdot \mathrm{d}^{-1}$

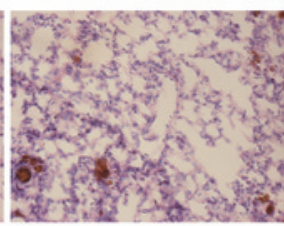

$424.2 \mathrm{mg} \mathrm{kg}^{-1} \cdot \mathrm{d}^{-1}$
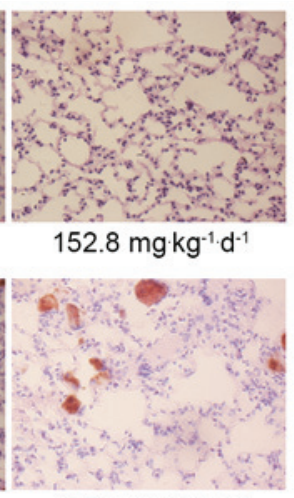

$707.0 \mathrm{mg} \cdot \mathrm{kg}^{-1} \cdot \mathrm{d}^{-1}$
Figure 3. Hematoxylin and eosin staining results following the acute toxicity assay. The lung tissue was stained with hematoxylin and eosin to observe the conditions of edema, deformation and necrosis in cells following the acute toxicity assay (magnification, x200).

group of the same gender $\left(\mathrm{F}_{\rho}=38.58, \mathrm{~F}_{\delta}=12.56, \mathrm{P}<0.05\right)$. With the increasing dose, the lung/body ratio also increased accordingly. The co-efficient of the other organs in each treatment group exhibited no significant difference when compared with the control group $(\mathrm{P}>0.05)$.

The routine blood test demonstrated that the total number of white blood cells in the treatment groups were significantly higher compared with the control group of the same gender $\left(\mathrm{F}_{\mathrm{P}}=93.37, \mathrm{~F}_{\delta}=80.04, \mathrm{P}<0.05\right)$. The remaining indexes revealed no significant differences between the different groups (Table III). The blood biochemical assay indicated that there was no significant difference in blood biochemistry indexes between each treatment group and control group of the same gender (Table IV). 
Table II. Effects of Ang2-CMNPs on organ co-efficiencies of male rats (\%).

\begin{tabular}{|c|c|c|c|c|}
\hline Organ co-efficiency & Control & Low-dose & Middle-dose & High-dose \\
\hline ঐHHeart/body & $0.52 \pm 0.08$ & $0.52 \pm 0.13$ & $0.46 \pm 0.04$ & $0.47 \pm 0.07$ \\
\hline 'Liver/body & $5.73 \pm 0.48$ & $5.21 \pm 0.05$ & $5.09 \pm 0.17$ & $4.75 \pm 0.37$ \\
\hline Spleen/body & $0.32 \pm 0.03$ & $0.44 \pm 0.03$ & $0.38 \pm 0.03$ & $0.49 \pm 0.13$ \\
\hline §Lung/body & $0.57 \pm 0.06$ & $0.74 \pm 0.05^{\mathrm{a}}$ & $0.81 \pm 0.03^{\mathrm{a}}$ & $0.84 \pm 0.00^{\mathrm{a}}$ \\
\hline §Kidney/body & $0.97 \pm 0.15$ & $1.04 \pm 0.18$ & $1.03 \pm 0.06$ & $0.92 \pm 0.00$ \\
\hline +Heart/body & $0.54 \pm 0.10$ & $0.50 \pm 0.01$ & $0.49 \pm 0.04$ & $0.45 \pm 0.05$ \\
\hline OLiver/body & $5.14 \pm 0.21$ & $5.13 \pm 0.67$ & $4.86 \pm 0.46$ & $5.01 \pm 0.38$ \\
\hline OSpleen/body & $0.41 \pm 0.03$ & $0.43 \pm 0.03$ & $0.49 \pm 0.04$ & $0.35 \pm 0.09$ \\
\hline QLung/body & $0.57 \pm 0.03$ & $0.77 \pm 0.03^{\mathrm{a}}$ & $0.79 \pm 0.04^{\mathrm{a}}$ & $0.88 \pm 0.01^{\mathrm{a}}$ \\
\hline †Kidney/body & $1.04 \pm 0.11$ & $1.01 \pm 0.07$ & $0.94 \pm 0.04$ & $0.97 \pm 0.08$ \\
\hline
\end{tabular}

${ }^{\mathrm{a}} \mathrm{P}<0.05$ vs. control group. Low-dose, middle-dose and high-dose groups received 35.35, 70.70 and $353.50 \mathrm{mg} \cdot \mathrm{kg}^{-1} \cdot \mathrm{d}^{-1} \mathrm{Ang} 2-\mathrm{CMNPs}$, respectively. Saline was administered to the control group. Ang2-CMNPs, angiopoietin-2-small interfering RNA plasmid chitosan magnetic nanoparticles.

Table III. Effects of Ang2-CMNPs on blood routine indexes of rats.

\begin{tabular}{|c|c|c|c|c|}
\hline Group & $\begin{array}{l}\text { Red cell count } \\
\left(10^{12} \text { cells } / 1\right)\end{array}$ & $\begin{array}{l}\text { White cell count } \\
\qquad\left(10^{9} \text { cells } / 1\right)\end{array}$ & $\begin{array}{l}\text { Hemoglobin } \\
\text { content }(\mathrm{g} / \mathrm{l})\end{array}$ & $\begin{array}{c}\text { Blood platelet } \\
\text { count }\left(10^{9} \text { cells } / 1\right)\end{array}$ \\
\hline Control & $6.78 \pm 0.58$ & $3.45 \pm 0.26$ & $133.60 \pm 4.32$ & $480.00 \pm 30.33$ \\
\hline đLow-dose & $6.81 \pm 0.31$ & $5.05 \pm 0.35^{\mathrm{a}}$ & $133.00 \pm 5.18$ & $492.00 \pm 25.61$ \\
\hline Middle-dose & $6.79 \pm 0.32$ & $5.58 \pm 0.38^{\mathrm{a}}$ & $138.00 \pm 5.66$ & $478.00 \pm 38.68$ \\
\hline${ }^{\lambda}$ High-dose & $6.66 \pm 0.28$ & $6.99 \pm 0.31^{\mathrm{a}}$ & $139.20 \pm 5.04$ & $484.00 \pm 37.20$ \\
\hline qControl & $6.73 \pm 0.39$ & $3.48 \pm 0.27$ & $130.80 \pm 6.31$ & $464.00 \pm 31.37$ \\
\hline †Low-dose & $6.69 \pm 0.34$ & $5.06 \pm 0.26^{\mathrm{a}}$ & $133.20 \pm 3.06$ & $478.00 \pm 41.18$ \\
\hline qMiddle-dose & $6.80 \pm 0.35$ & $5.46 \pm 0.44^{\mathrm{a}}$ & $136.40 \pm 7.03$ & $478.00 \pm 44.00$ \\
\hline qHigh-dose & $6.62 \pm 0.29$ & $7.15 \pm 0.23^{\mathrm{a}}$ & $136.40 \pm 4.45$ & $466.00 \pm 48.83$ \\
\hline
\end{tabular}

${ }^{\mathrm{a}} \mathrm{P}<0.05$ vs. control group. Low-dose, middle-dose and high-dose groups received 35.35, 70.70 and $353.50 \mathrm{mg} \cdot \mathrm{kg}^{-1} \cdot \mathrm{d}^{-1} \mathrm{Ang} 2-\mathrm{CMNPs}$, respectively. Saline was administered to the control group. Ang2-CMNPs, angiopoietin-2-small interfering RNA plasmid chitosan magnetic nanoparticles.

The H\&E staining revealed that the alveolar wall of the middle- and high-dose group was thickened and exhibited mild fibrosis, and red blood cells leaked from the alveolar cavity (Fig. 5). The Prussian blue staining demonstrated that blue particles in the middle- and high-dose group were scattered inside the lungs, that the particles aggregated in lungs and were engulfed by pulmonary phagocytes, and inflammatory reactions existed around the lungs (Fig. 6). The control group and the low-dose group demonstrated no abnormalities. The remaining organs exhibited no obvious abnormality.

\section{Discussion}

Nano-targeted drug delivery systems can overcome the limitation of traditional chemotherapies, and therefore, have become a novel and prosperous tumor treatment method. In MTDDS, the magnetic nanoparticles may be used as an ideal carrier for direct targeted accumulation into the tumor tissues, thus selectively releasing the therapeutic molecules (9).
MTDDS predominantly consists of three parts: i) Magnetic material; ii) the frame material; and iii) the drug. The most representative magnetic material at present is $\mathrm{Fe}_{3} \mathrm{O}_{4}$ powder, which can not only provide magnetism for the targeting drugs, but can also load the drugs for targeted therapy (10). The drugs used in MTDDS currently include adriamycin (11), folic acid (12), cisplatin and insulin (13). The frame material is the part connecting the magnetic material and the drug, including glucans (14) and chitosan (15). The specific targeting characteristics of the magnetic nano-carrier include active and passive targeting (16). Active targeting vectors have a higher specificity compared with passive targeting vectors, and include the ligand or antibody coupling of the targeted cells (17), or are directly aggregated in the targeted tissues under the influence of an external magnetic field to achieve its targeting property.

Iron is one of the essential trace elements, and human tissues store and transport it using hemoglobin, transferrin, ferritin and transferrin hemosiderin. Excessive iron can be 


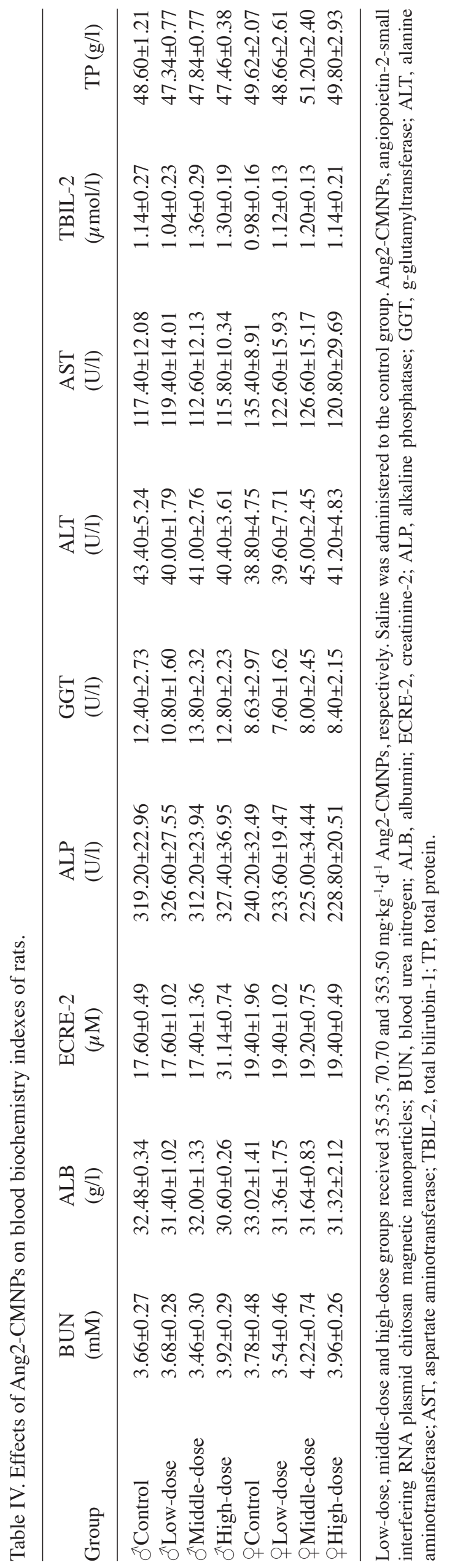

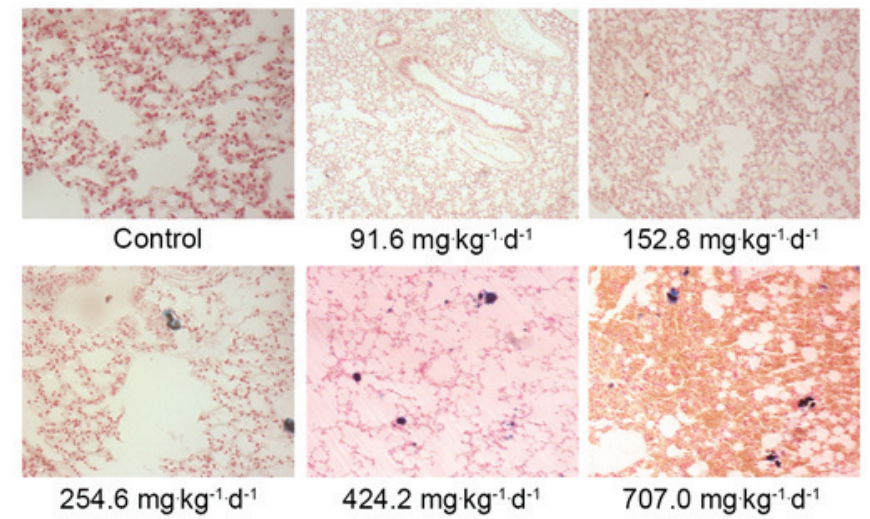

Figure 4. Prussian blue staining results following the acute toxicity assay. The lung tissue was stained with Prussian blue to observe iron-particle deposition in cells following the acute toxicity assay. (magnification: Control, $\mathrm{x} 200 ; 91.6 \mathrm{mg} \cdot \mathrm{kg}^{-1} \cdot \mathrm{d}^{-1}, \mathrm{x} 100 ; 152.8 \mathrm{mg} \cdot \mathrm{kg}^{-1} \cdot \mathrm{d}^{-1}, \mathrm{x} 200 ; 254.6 \mathrm{mg} \cdot \mathrm{kg}^{-1} \cdot \mathrm{d}^{-1}, \mathrm{x} 200$; $\left.424.2 \mathrm{mg} \cdot \mathrm{kg}^{-1} \cdot \mathrm{d}^{-1}, \mathrm{x} 200 ; 707.0 \mathrm{mg} \cdot \mathrm{kg}^{-1} \cdot \mathrm{d}^{-1}, \mathrm{x} 200\right)$.

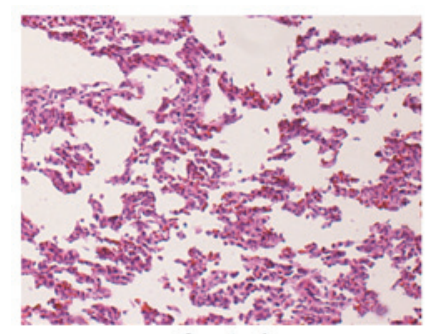

Control

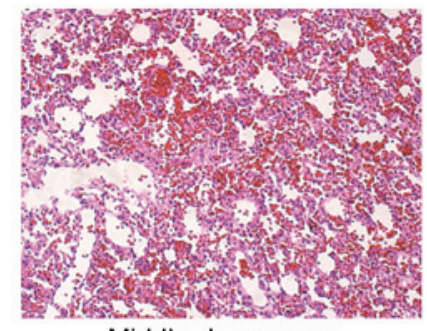

Middle-dose group

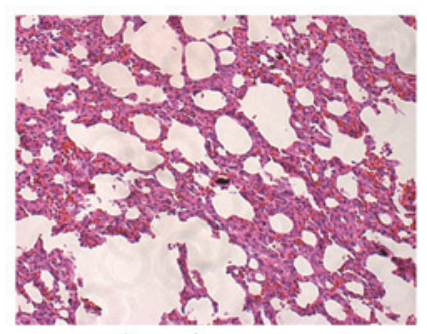

Low-dose group

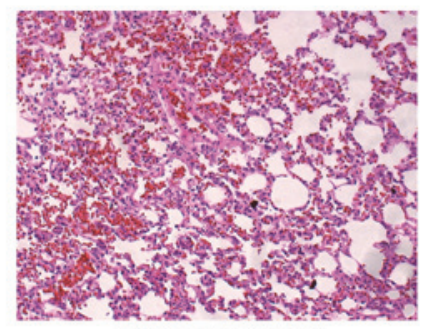

High-dose group
Figure 5. Hematoxylin and eosin staining results following the chronic toxicity assay. The lung tissue was stained with hematoxylin and eosin to observe the conditions of edema, deformation and necrosis in cells following the chronic toxicity assay (magnification, $\mathrm{x} 100$ ).

discharged via urine and sweat. As a gene carrier, chitosan is a material that has received great attention in recent years (18). It is a cationic basic polysaccharide polymer, and is widely used in the food and pharmaceutical industry for its good compatibilities (19). As a natural polysaccharide, it is of high safety. In previous years, chitosan nanoparticles have undergone vast developments in novel drug-sustained release systems for their high specificity, sensitivity, improved bioavailability and low toxicity (20). The present study applied self-made chitosan magnetic nanoparticles that use $\mathrm{Fe}_{3} \mathrm{O}_{4}$ as the core to connect Ang2-siRNA plasmids in the formation of Ang2-CMNPs. When chitosan is bound with magnetic $\mathrm{Fe}_{3} \mathrm{O}_{4}$ nanoparticles, the size and structure is altered (21). Therefore, the nature and intensity of biological effects produced by these nanoparticles to the body will also change, thus generating certain impact on the body. 
Acute toxicity is an important index to evaluate the safety of drugs. In the present study, the acute toxicity assay revealed that the mice in groups 3-5 exhibited short-term staggering, reduced activities and accelerated breathing, as well as transient reduction of eating; however all mice recovered normally following experimentation. The weight gains in the treatment groups revealed no significant difference when compared with the control group, and no mouse in any group died, indicating that acute toxicity was low. Following sacrificing and dissection of the mice, it was revealed that the lungs in groups 3-5 exhibited uneven dark red coloring. H\&E staining revealed acute pulmonary congestion and Prussian blue staining demonstrated blue particles scattering inside the lungs. These particles were aggregated inside the lungs and phagocytized by lung phagocytes. The control group and the low-dose group demonstrated no obvious abnormalities. This indicated that low-dose Ang2-CMNPs caused no obvious acute toxicity in the mice.

In the chronic toxicity assay, the rats in all groups exhibited normal feeding and drinking activity following injection of Ang2-CMNPs and no animal died. No significant impact was observed on weight gain and hepatoenteric functions. Following the sacrifice and dissection of the rats, the middleand high-dose group exhibited uneven dark red coloring in the lungs. H\&E staining revealed chronic pulmonary congestion and pulmonary inflammation, whilst Prussian blue staining demonstrated more particles aggregated inside the lungs; the control group and the low-dose group exhibited no such abnormality. Therefore, it can be presumed that the non-toxic dose of Ang2-CMNPs was $>35.35 \mathrm{mg} \cdot \mathrm{kg}^{-1} \cdot \mathrm{d}^{-1}$. As for the organ co-efficients, the lung/body ratios in the high-, middleand low-dose group were significantly higher compared with the control group, and the blood routine revealed that the total number of white blood cells in each treatment group was significantly higher compared with the control group. Therefore, it can be suggested that the target organ for the Ang2-CMNP-induced toxicity is predominantly the lungs; the repeated stimulation of particles to the lungs will induce chronic lung inflammation and mild fibrosis.

The surface functionalization, colloidal stability and biocompatibility of the magnetic nanoparticles are crucial for their biomedical applications (22), and the toxicity of the nanoparticles is often closely associated with their sizes. When the particle diameter is $<100 \mathrm{~nm}$, the toxicity is predominantly decided by the nature of the particles or the surface-attached materials, but when the particle size is larger, death can often be caused by the embolism of capillaries and small blood vessels by the particles. In the present study, the results demonstrated that Ang2-CMNPs predominantly caused damage in the lungs. Since the specific surface areas of nanoparticles are significantly increased with the decreased particle size, so is the particle surface energy. Therefore, they would easily mutually aggregate at a high concentration. It can be presumed that the reason for Ang2-CMNP-induced lung damage is that, when a large number of microparticles enter the circulation of the mice, they will firstly reach the lungs. The aggregation of the particles will then block the pulmonary vessels, thus leading to the observed acute pulmonary congestion. In the chronic toxicity assay, the long-term repeated injection of the particles
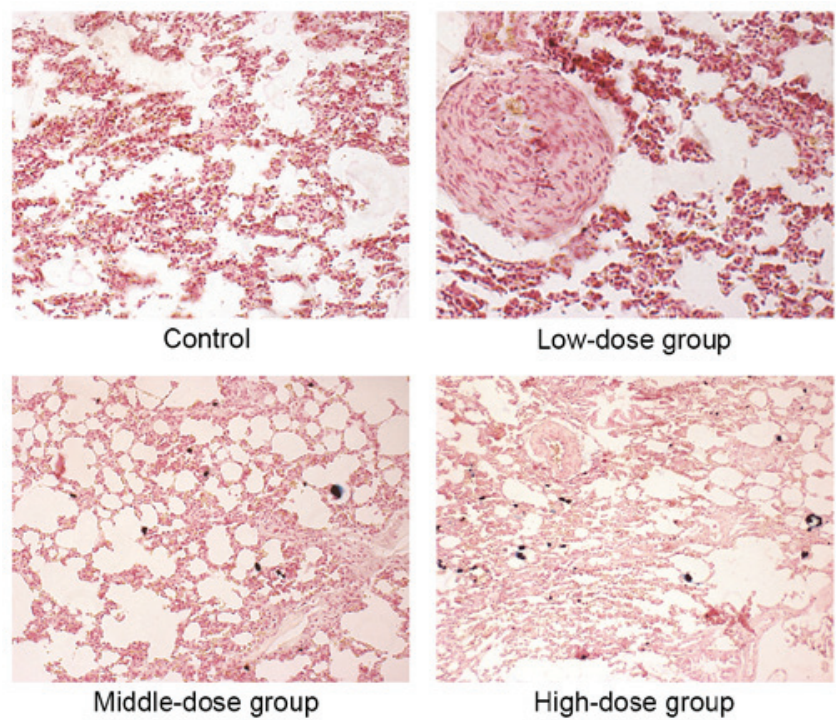

Figure 6. Prussian blue staining results following the chronic toxicity assay The lung tissue was stained with Prussian blue to observe iron-particle deposition in cells following the acute toxicity assay (magnification: Control, x100; low-dose $35.35 \mathrm{mg} \cdot \mathrm{kg}^{-1} \cdot \mathrm{d}^{-1}$ Ang2-CMNPs, $\mathrm{x} 200$; middle-dose $70.70 \mathrm{mg} \cdot \mathrm{kg}^{-1} \cdot \mathrm{d}^{-1}$ Ang2-CMNPs, x 100; high-dose $353.50 \mathrm{mg} \cdot \mathrm{kg}^{-1} \cdot \mathrm{d}^{-1}$ Ang2-CMNPs, x100).

via the tail vein led to chronic pulmonary congestion in rats, as well as simultaneous pulmonary inflammation and partial fibrosis. Since the unaggregated particles are small in size, they can escape phagocytosis by the liver and spleen, so no particle deposition was observed around the liver and spleen. The low-dose group presented no organ damage, so it can be speculated that, in a certain concentration range, CMNPs will be safe and not cause side effects towards the body. This non-toxic dose was determined as $>35.35 \mathrm{mg} \cdot \mathrm{kg}^{-1} \cdot \mathrm{d}^{-1}$. Based on the conversion method of equivalent dose co-efficient, the non-toxic dose in humans should be $>222.71 \mathrm{mg} \cdot \mathrm{kg}^{-1} \cdot \mathrm{d}^{-1}$ for 14 day, overall a total of $3,117.87 \mathrm{mg} \cdot \mathrm{kg}^{-1}$, which is significantly higher compared with the quantity required clinically. Therefore, this dose is relatively safe. Increasing the dispersion degree of the particles may reduce the aggregation at higher concentrations, thus reducing the toxicity.

One of the major challenges faced by gene therapy is the selection of vector system in gene therapy (23). The results of the present study demonstrated that, Ang2-CMNPs have good security, so they can be considered as a vector for targeted gene therapy. Furthermore, the study has also laid a foundation for the in vivo targeting intervention experiments towards the angiogenesis and tumor growth of transplanted malignant melanoma in nude mice in the future.

\section{Acknowledgements}

The present study was supported by the Foundation of National Key Clinical Specialty Discipline Construction Program, Scientific Research Foundation of National Health Planning Scientific Research Foundation-Joint Research Projects of Fujian Provincial Health and Education (no. WKJ-FJ-03), Projects of Fujian Provincial Natural Science Foundation (no. 2012J01125) and Youth Scientific Research Subject of Fujian Provincial Health and Family Planning Commission (no. 2015-1-45). 


\section{References}

1. Wu F, Lin GZ and Zhang JX: An overview of cancer incidence and trend in China. Zhong Guo Ai Zheng 21: 81-83, 2012 (In Chinese).

2. Venza M, Visalli M, Beninati C, De Gaetano GV, Teti D and Venza I: Cellular mechanisms of oxidative stress and action in melanoma. Oxid Med Cell Longev 2015: 481782, 2015.

3. Schlaak M, Kreuzberg N, Mauch C and Kurschat P: Personalized therapy concepts for malignant melanoma. Internist (Berl) 54: 188-193, 2013 (In German)

4. Unger E, Porter T, Lindner J and Grayburn P: Cardiovascular drug delivery with ultrasound and microbubbles. Adv Drug Deliv Rev 72: 110-126, 2014.

5. Zeinali Sehrig F, Majidi S, Nikzamir N, Nikzamir N, Nikzamir M and Akbarzadeh A: Magnetic nanoparticles as potential candidates for biomedical and biological applications. Artif Cells Nanomed Biotechnol 44: 918-927, 2016.

6. Ishii T, Okahata Y and Sato T: Mechanism of cell transfection with plasmid/chitosan complexes. Biochim Biophys Acta 1514: 51-64, 2001.

7. Hoet PH, Brüske-Hohlfeld I and Salata OV: Nanoparticles-known and unknown health risk. Nanobiotechnology 2: 12, 2004.

8. Nel A, Xia T, Mädler L and Li N: Toxic potential of materials at the nanolevel. Science 311: 622-627, 2006.

9. Unsoy G, Khodadust R, Yalcin S, Mutlu P and Gunduz U: Synthesis of Doxorubicin loaded magnetic chitosan nanoparticles for $\mathrm{pH}$ responsive targeted drug delivery. Eur J Pharm Sci 62: 243-250, 2014.

10. Peng XH, Qian X, Mao H, Wang AY, Chen ZG, Nie S and Shin DM: Targeted magnetic iron oxide nanoparticles for tumor imaging and therapy. Int J Nanomedicine 3: 311-321, 2008.

11. Shi Z, Guo R, Li W, Zhang Y, Xue W, Tang Y and Zhang Y: Nanoparticles of deoxycholic acid, polyethylene glycol and folic acid-modified chitosan for targeted delivery of doxorubicin. J Mater Sci Mater Med 25: 723-731, 2014.

12. Wang J, Wang M, Zheng M, Guo Q, Wang Y, Wang H, Xie X, Huang $\mathrm{F}$ and Gong R: Folate mediated self-assembled phytosterol-alginate nanoparticles for targeted intracellular anticancer drug delivery. Colloids Surf B Biointerfaces 129: 63-70, 2015.
13. Shen JM, Xu L, Lu Y, Cao HM, Xu ZG, Chen T and Zhang HX: Chitosan-based luminescent/magnetic hybrid nanogels for insulin delivery, cell imaging and antidiabetic research of dietary supplements. Int J Pharm 427: 400-409, 2012.

14. Peng M, Li H, Luo Z, Kong J, Wan Y, Zheng L, Zhang Q, Niu H, Vermorken A, Van de Ven W, et al: Dextran-coated superparamagnetic nanoparticles as potential cancer drug carriers in vivo. Nanoscale 7: 11155-11162, 2015.

15. Sadighian S, Hosseini-Monfared H, Rostamizadeh K and Hamidi M: pH-triggered magnetic-chitosan nanogels (MCNs) for doxorubicin delivery: Physically vs. Chemically cross linking approach. Adv Pharm Bull 5: 115-120, 2015.

16. Yu B, Tai HC, Xue W, Lee LJ and Lee RJ: Receptor-targeted nanocarriers for therapeutic delivery to cancer. Mol Membr Biol 27: 286-298, 2010.

17. Torchilin VP: Passive and active drug targeting: Drug delivery to tumors as an example. Handb Exp Pharmacol 3-53, 2010.

18. Mansouri S, Lavigne P, Corsi K, Benderdour M, Beaumont E and Fernandes JC: Chitosan-DNA nanoparticles as non-viral vectors in gene therapy: Strategies to improve transfection efficacy. Eur J Pharm Biopharm 57: 1-8, 2004.

19. Sionkowska A, Wisniewski M, Skopinska J, Kennedy CJ and Wess TJ: Molecular interactions in collagen and chitosan blends. Biomaterials 25: 795-801, 2004.

20. Ghadi A, Mahjoub S, Tabandeh F and Talebnia F: Synthesis and optimization of chitosan nanoparticles: Potential applications in nanomedicine and biomedical engineering. Caspian J Intern Med 5: 156-161, 2014.

21. Chang YC and Chen DH: Preparation and adsorption properties of monodisperse chitosan-bound $\mathrm{Fe} 3 \mathrm{O} 4$ magnetic nanoparticles for removal of $\mathrm{Cu}(\mathrm{II})$ ions. J Colloid Interface Sci 283: 446-451, 2005.

22. Thorat ND, Otari SV, Patil RM, Bohara RA, Yadav HM, Koli VB, Chaurasia AK and Ningthoujam RS: Synthesis, characterization and biocompatibility of chitosan functionalized super paramagnetic nanoparticles for heat activated curing of cancer cells. Dalton Trans 43: 17343-17351, 2014.

23. O'Rorke S, Keeney M and Pandit A: Non-viral polyplexes: Scaffold mediated delivery for gene therapy. Prog Polym Sci 35: 441-458, 2010 